\title{
Wavelength Markers for Malaria (Plasmodium Falciparum) Infected and Uninfected Red Blood Cells for Ring and Trophozoite Stages
}

\author{
Jerry Opoku-Ansah ${ }^{1}$, Moses Jojo Eghan ${ }^{1}$, Benjamin Anderson ${ }^{1} \&$ Johnson Nyarko Boampong ${ }^{2}$ \\ ${ }^{1}$ Department of Physics, School of Physical Sciences, University of Cape Coast, Laser and Fibre Optics Centre \\ (LAFOC), Cape Coast, Ghana \\ ${ }^{2}$ Department of Biomedical and Forensic Sciences, School of Biological Sciences, University of Cape Coast, \\ Cape Coast, Ghana \\ Correspondence: Moses Jojo Eghan, University of Cape Coast, School of Physical Sciences, Department of \\ Physics, Laser and Fibre Optics Centre (LAFOC), Cape Coast, Ghana. Tel: 233-244-255-642; Fax: \\ 233-332-132-446. E-mail: meghan@ucc.edu.gh
}

Received: December 18, 2013 Accepted: January 7, 2014 Online Published: February 20, 2014

doi:10.5539/apr.v6n2p47

URL: http://dx.doi.org/10.5539/apr.v6n2p47

\begin{abstract}
Malaria parasite, Plasmodium falciparum, uses haemoglobin in host red blood cells (RBCs) as a major source of nutrient in ring and trophozoite stages. This brings about changes in the morphology and functional characteristics of the RBCs. We investigate malaria infected RBCs and uninfected RBCs-ring and trophozoite stages using multispectral imaging technique. Four spectral bands were found to be markers for identifying infected and uninfected RBCs: $435 \mathrm{~nm}$ and $660 \mathrm{~nm}$ were common markers for the two stages whiles $590 \mathrm{~nm}$ and $625 \mathrm{~nm}$ were markers for the ring and the trophozoite stages respectively. These four spectral bands may offer potential diagnostic markers for identifying infected and uninfected RBCs, as well as distinguishing ring and trophozoite stages.
\end{abstract}

Keywords: multispectral imaging, Plasmodium falciparum, red blood cells (RBCs), principal component analysis (PCA)

\section{Introduction}

Malaria parasites, Plasmodium falciparum ( $P$. falciparum), found in RBCs, remain the major contributor to morbidity and mortality especially in poor countries (Sachs \& Melaney, 2002; Hay, Guerra, Tatem, Noor, \& Snow, 2004; Paton et al., 2011). According to the World Health Organization (WHO), malaria parasites cause more than

1 million deaths with many cases of infections reported annually (Makler, Palmer, \& Ager, 1998; Ross, Pritchard, Rubin, \& Duse, 2006; Tek, Dempster, \& Kale, 2009; Savkare \& Narote, 2011). Infants and children account for most of the mortality from malaria and the disease accounts for ninety percent of the deaths of children in Africa (Amexo, Tolhurst, Barnish \& Bates, 2004). Mortality caused by malaria parasites in most rural areas in Africa remains high because there is inadequate access to treatment (Weatherall et al., 2002).

Generally, the $P$. falciparum has a complex life cycle that consists of an asexual phase in the host and a sexual phase in the mosquito. The erythrocytic asexual phase involves the merozoites entering into the RBCs to become the ring stage. At the ring stage the parasite can transform to trophozoite and subsequently schizont or gametocyte after several cycles (Arora, Park, Mauser, Chakrabarti, \& Schulte, 2011). The determinant of this transformation is underpinned by the digestion of haemoglobin $(\mathrm{Hb})$ by the parasite using specific enzymes.

Studies have suggested that the discriminating spectral bands for infected RBCs ( $i \mathrm{RBCs})$ and uninfected RBCs $(u \mathrm{RBCs})$ are found in the region 590-700 $\mathrm{nm}$ (Omucheni, 2012). Combined micro-Raman and micro-absorption techniques also show a comparative analysis of the $i$ RBCs and $u$ RBCs in the UV-visible region (Arora et al., 2011). Furthermore, an explanation model based on core-shell Mie scattering calculations presented the analysis of the $i \mathrm{RBCs}$ and $u \mathrm{RBCs}$ in the UV-visible region (Yulia, Patel, \& Garcia-Rubio, 2010). These opinions therefore calls for further studies in order to identify the specific spectral band(s) that can be used as a marker(s) for $i \mathrm{RBCs}$ and $u \mathrm{RBCs}$. Discriminating the stage of the malaria parasite will help in precise diagnosis and direct control of their development (Moore et al., 2006). 
Optical identification of tissues irregularities needs methods that can measure a change in the cells. This identification has been achieved using techniques such as bioluminescence signals, fluorescence microscopy, point-scanning laser confocal microscopy and photoacoustic microscopy imaging (Rice, Cable, \& Nelson, 2001; Graves, Ripoll, Weissleder, \& Ntziachristos, 2003; Levenson \& Mansfield, 2006; Zhang, Maslov, Stoica, \& Wang, 2006; Zhang, Maslov, \& Wang, 2007; Zhang, Hong, \& Cai, 2011). Among these techniques, multispectral imaging (MSI) is commonly used (Hiraoka, Shimi, \& Haraguchi, 2002; Zhou \& El-Deiry, 2009). MSI is a blend of images obtained from spectroscopy, in that spatial as well as spectral information emanating from microscopic samples can be extracted beyond the visible region (Coffey, 2012; Hu et al., 2005; Teikari, 2008). MSI approach has been used in identifying multiple tissue structures or cell types (Levenson, Lynch, Kobayashi, Backer, Backer, 2008), utilizing multiplexed quantum-dot labels in tissue specimens (Levenson \& Mansfield, 2006), and combination with fluorescence microscopy in small-animal imaging to produce enhanced sensitivity, reliable quantitation and resolved multiple simultaneous signals (Mansfield, Gossage, Hoyt, \& Levenson, 2005). In all MSI techniques, no studies have been done so far in applying multivariate techniques to identify precise spectral band(s) for discriminating $i$ RBCs and $u$ RBCs.

\section{Materials, Method and Analysis}

\subsection{Samples}

Samples used for this research work were cultured RBCs, with both infected and uninfected cells, stained with Giemsa dye on thin film slides, and grouped into ring and trophozoite stages. The cultured RBCs were obtained from ten (10) individuals, each contributing ten (10) slides each for a stage. These slides were obtained from the Department of Biomedical and Forensic Sciences, School of Biological Sciences, University of Cape Coast (UCC).

\subsection{Multispectral Imaging}

Multispectral images of the thin blood smear slides were acquired in transmission mode, using Multispectral Light Emitting Diodes Imaging Microscope system (MSLEDIM), which employed nine light emitting diodes (LEDs), as implemented in Brydegaard et al. (Brydegaard, Merdasa, Jayaweera, Ålebring, \& Svanberg, 2011). The nine LEDs emit a total of thirteen spectral bands for the system. One of the LEDs is a triple-band ( $470 \mathrm{~nm}$, $525 \mathrm{~nm}$ and $810 \mathrm{~nm})$ and two others are dual-bands $(375 \mathrm{~nm}, 400 \mathrm{~nm}$ and $625 \mathrm{~nm}, 850 \mathrm{~nm})$ whiles the remaining six are of single-bands $(435 \mathrm{~nm}, 590 \mathrm{~nm}, 660 \mathrm{~nm}, 700 \mathrm{~nm}, 750 \mathrm{~nm}$, and $940 \mathrm{~nm}$ ). A LabVIEW (National Instrument, NI) program is used to control the LEDs and the image acquisition. In acquiring images, the $590 \mathrm{~nm}$ spectral band is used to adjust the camera settings, (i.e. the gain and the exposure time). The images of the thin blood smear slides were acquired in grayscale and saved in tagged image file format (TIFF) for each of the thirteen spectral bands. The images were imported into a MATrix LABoratory (Matlab) (R2010a Matlab 7.10.0, Mathworks Inc.) platform and the pixel intensities representing $i \mathrm{RBCs}$ and $u \mathrm{RBCs}$, were extracted.

\subsection{Principal Component Analysis}

Principal Component Analysis (PCA) was performed on the intensity data using Matlab algorithm. PCA is a non-parametric method of extracting relevant information from the multidimensional data set. The reduction of the complex multidimensional data set to a lower dimension reveals the principal hidden or latent factors.

Data set, $X$ of $m$ observations and $n$ variables is centered $X_{c}$ such that the elements of the matrix of dimension $m \times n$ are around the sample mean of zero. The $X_{c}$ is then converted into covariant matrix $S$ defined as

$$
S=\frac{1}{m-1} X_{c}^{\prime} X_{c}
$$

where $X_{c}{ }^{\prime}$ denotes the matrix transpose of $X_{c}$. This square, symmetric, nonsingular covariant matrix $S$ is further transformed into a diagonal matrix using the relation below,

$$
M=\beta^{\prime} S \beta
$$

where the columns of $\beta$ contain the eigenvectors of $S$ and $M$ is a diagonal matrix with the eigenvalues along the diagonal. $\beta$ is used to obtain new variables called Principal Components (PCs).

Two sets of PCA analysis were done; one with all the 13 variables (spectral bands) and 252 observations (intensities) $(252 \times 13$ data points), the second was performed with ten (10) variables (ten unique individuals). Scree plots were used to determine the number of principal components (PCs) appropriate for discrimination and classification. The PCA reduced the dimensionality of the observations, which are the intensity values at the various spectral bands. 


\section{Results and Discussions}

Figure 1a shows the grayscale image of a thin blood smear slide sample with the $590 \mathrm{~nm}$ LED source. The image shows a bright background interspersed with spots representing $i \mathrm{RBCs}$ and $u$ RBCs. This spectral band was used as a standard due to the camera's sensitivity to it. Figures $1 \mathrm{~b}-\mathrm{d}$ represent grayscale images of the same thin blood smear slide sample with $435 \mathrm{~nm}, 700 \mathrm{~nm}$, and $940 \mathrm{~nm}$ LED sources respectively. The images have the same dimensions but different grayscales. The other images (not shown) have the same dimensions as in Figure 1 and also show different grayscales. The different grayscales are as a result of selective spectral band absorption of the LED sources.

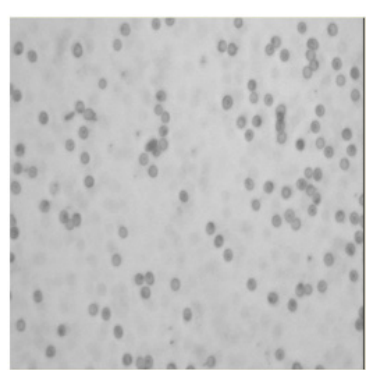

(a)

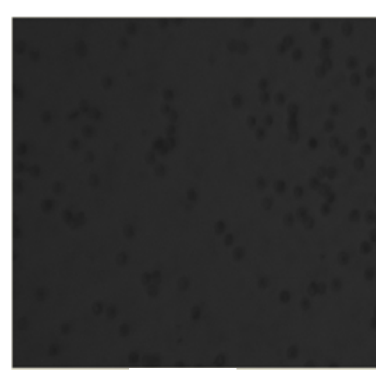

(b)

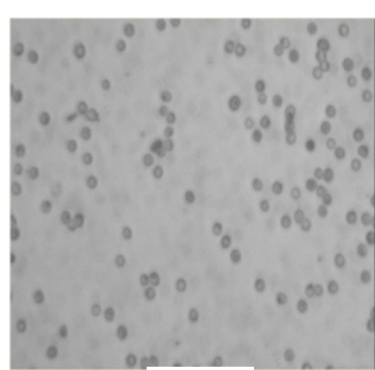

(c)

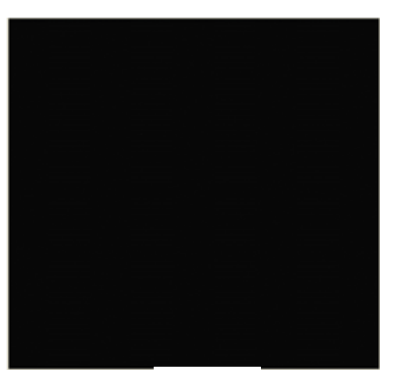

(d)

Figure 1. Some of the grayscale images captured from the thin blood smear slides with ring stage of $P$. falciparum using the Multispectral Light Emitting Diodes Imaging Microscope system at (a) $590 \mathrm{~nm}$ (b) $435 \mathrm{~nm}$, (c) $700 \mathrm{~nm}$ and (d) $940 \mathrm{~nm}$ spectral bands. The spots in the images represent the $i \mathrm{RBCs}$ and the $u \mathrm{RBCs}$

In Figure 2, we show the plots of the maximum pixel intensities of the $i \mathrm{RBCs}$ and the $u$ RBCs extracted from the grayscale images of the slides with the ring stage and the trophozoite stage of P.falciparum against the spectral bands of the LED light sources.

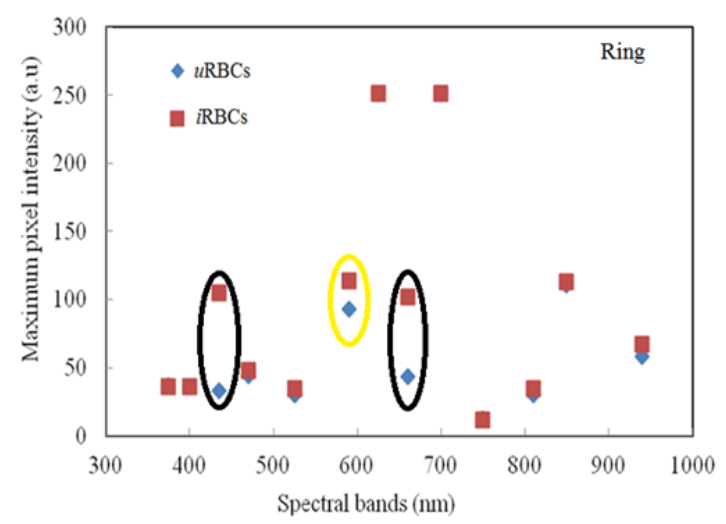

(a)

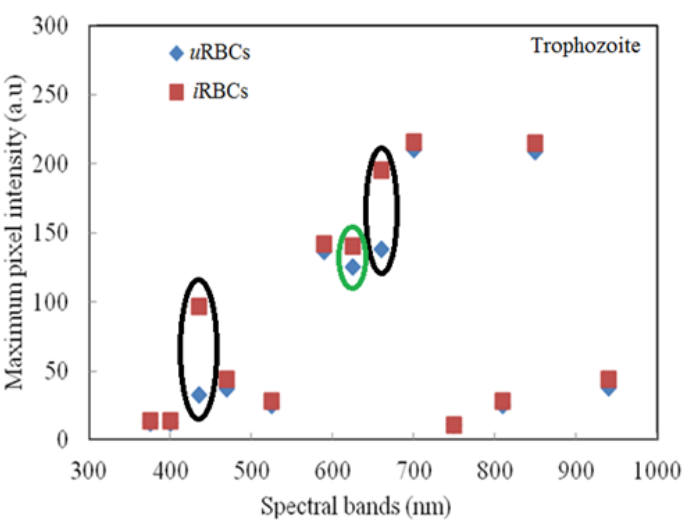

(b)

Figure 2. The maximum grayscale pixel intensities extracted from the images of the slides with (a) ring stage and (b) trophozoite stage of $P$. falciparum infected RBCs ( $i \mathrm{RBCs})$ and uninfected ( $u$ RBCs). The common spectra bands have been indicated with a black ring and the independent spectra band with yellow ring (Ring stage) and green ring (trophozoite stage)

In Figure 2a, $435 \mathrm{~nm}, 590 \mathrm{~nm}$, and $660 \mathrm{~nm}$, show differences in transmitted light intensities for ring stage $i$ RBCs and $u$ RBCs. Intensity difference of 10.0 a.u was used the criterion. Whilst in Figure $2 \mathrm{~b}, 435 \mathrm{~nm}, 625 \mathrm{~nm}$, and $660 \mathrm{~nm}$ depict differences in transmitted light intensities for trophozoite stage $i$ RBCs and $u$ RBCs. Thus $435 \mathrm{~nm}$ and $660 \mathrm{~nm}$ are common spectral bands depicting intensity differences for the two stages. But the $590 \mathrm{~nm}$ and $625 \mathrm{~nm}$ spectral bands depict intensities differences in Figures 2a (ring stage) and 2b (trophozoite stage) respectively. This indicates that $435 \mathrm{~nm}$ and $660 \mathrm{~nm}$ spectral bands are seen as markers for both ring and 
trophozoite stages of $i$ RBCs and $u$ RBCs. Whilst $590 \mathrm{~nm}$ and $625 \mathrm{~nm}$ spectral bands are distinct markers for ring and trophozoite stages of $i \mathrm{RBCs}$ and $u \mathrm{RBCs}$ respectively. This is an indication that the $i \mathrm{RBCs}$ more or less have their $\mathrm{Hb}$ either partially or completely digested together with the membrane proteins and membrane skeletal proteins by the parasite. The $i \mathrm{RBCs}$ therefore become less dense hence able to transmit more light (Goldberg, Slater, Cerami, \& Henderson, 1990; Moore et al., 2006). The intensity differences may be due to the breakdown of $\mathrm{Hb}$ by the parasite, the protein chain fragments are transported away for further digestion. Also absorption curves of haemoglobin $(\mathrm{Hb})$ have strong bands in the visible part of the electromagnetic spectrum. The molar extinction coefficient for $\mathrm{Hb}$ is very high from 405-450 nm (Soret band), and $660 \mathrm{~nm}$. For various parasitic stages (e.g. Ring and Trophozoite ), the presence of hemozoin or the decrease of $\mathrm{Hb}$ would increase transmission. Therefore, incident radiation in this range will be very highly absorbed by cells with high concentration of $\mathrm{Hb}$. Generally, transmitted light intensities of $i \mathrm{RBCs}$ were higher than that of $u$ RBCs.

Figure 3 depicts the scree plot for the thirteen (13) variables and 252 observations, which was used to select the principal components (PCs) that best explain the transmitted intensities obtained from the images. Three PCs retain the maximum variance of $98.9 \%$ cumulative variability of the intensity data. Out of the $98.9 \%, \mathrm{PC} 1, \mathrm{PC} 2$ and $\mathrm{PC} 3$ contributed $64.9 \%, 31.0 \%$ and $3.0 \%$ variability respectively. The PCs are proportional to the transmitted intensities by the $i \mathrm{RBCs}$ and $u$ RBCs. The first PC (PC1) is the linear combination of the intensity data with maximum variance, $\mathrm{PC} 2$ is the linear combination of the next maximum variance orthogonal to $\mathrm{PC} 1$. PC3 is the linear combination of the third maximum variance orthogonal to both PC1 and PC2 in that order.

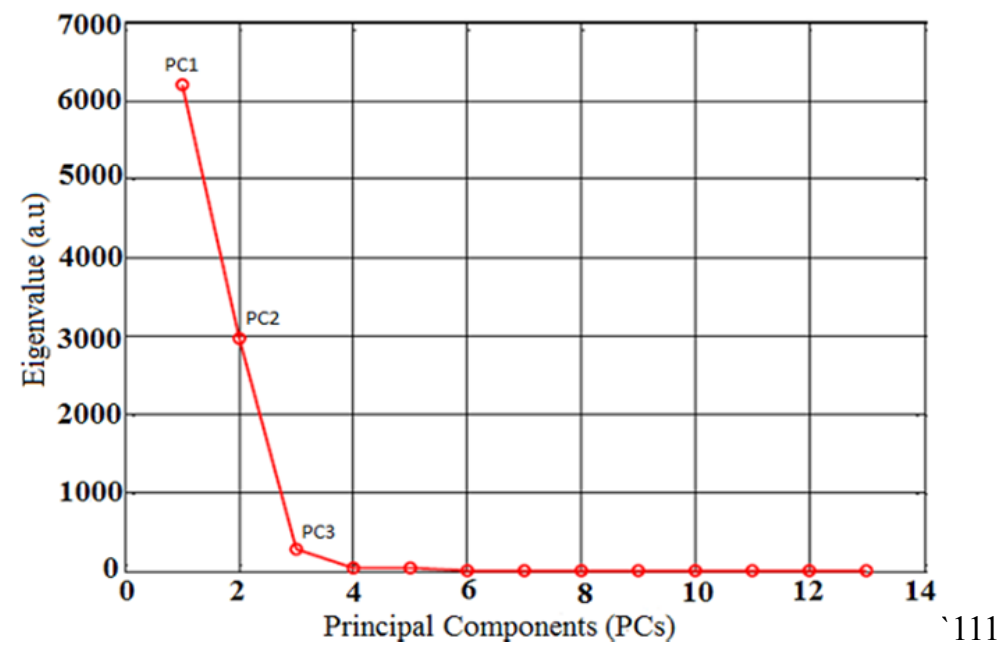

Figure 3. A scree plot indicating the eigenvalues of the Principal Components (PC's), which represent the weights of each PC

Figures 4 shows a scatter plot of the first three PCs of ring and trophozoite stages respectively of $i$ RBCs and $u \mathrm{RBCs}$ for all the thirteen spectral bands. There is a clear classification of $i \mathrm{RBCs}$ and $u \mathrm{RBCs}$ in both ring and trophozoite stages. 


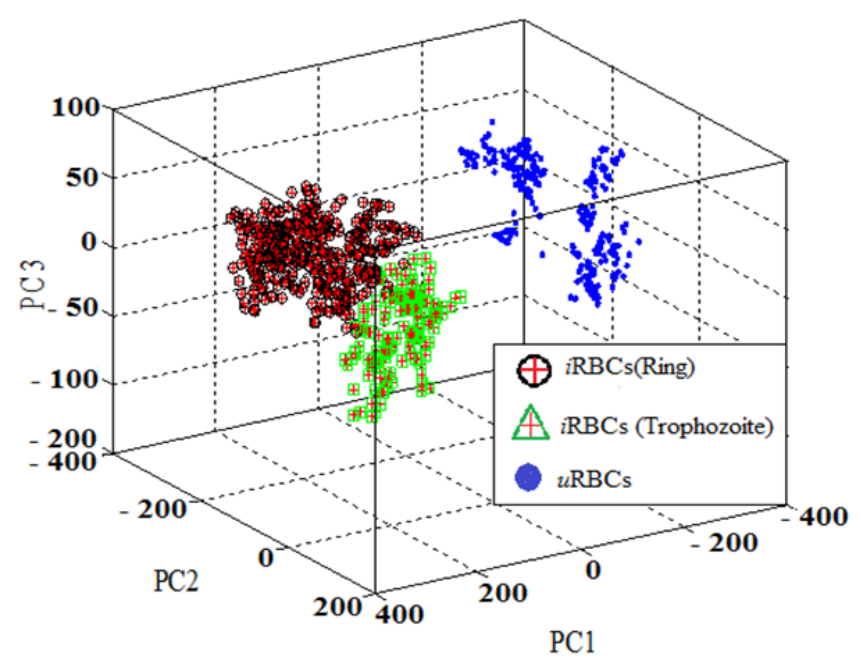

Figure 4. Scatter plot of the first three principal components from the scree plot (Figure 3 ) revealing $i$ RBCs at ring stage $(\oplus), i \operatorname{RBCs}$ at trophozoite stage $(\triangle)$ and $u \operatorname{RBCs}(\bullet)$ for all the thirteen (13) spectral bands

The first two coefficients of $\mathrm{PC} 1$, which represents the greatest amount of the variation in the sample and overall average light intensities detected, are considerably larger in magnitude suggesting that $\mathrm{PC} 1$ was dominated by two spectral bands. In Figure 4, the PC1 scores are between -200 and -400 and since PC1 has the highest variability, this indicates the consistency of $u$ RBCs characteristics. In Figures 5, 6, 7, and 8 we show the 3D scatter plots of the first three PCs which comprises of ten variables each (ten individuals) obtained from $435 \mathrm{~nm}$ $660 \mathrm{~nm}, 470 \mathrm{~nm}$, and $700 \mathrm{~nm}$ spectral bands respectively for $i \mathrm{RBCs}$ and $u$ RBCs at the two stages of the parasite. In Figures 5 and 6 , there is a discrete separation pattern between $i \mathrm{RBCs}$ and $u \mathrm{RBCs}$ for both ring stage and trophozoite stage. The 3 PCs (PC1, PC2, and PC3) of $u$ RBCs have negative scores, while the $i$ RBCs have its negative scores only in $\mathrm{PC} 3$.

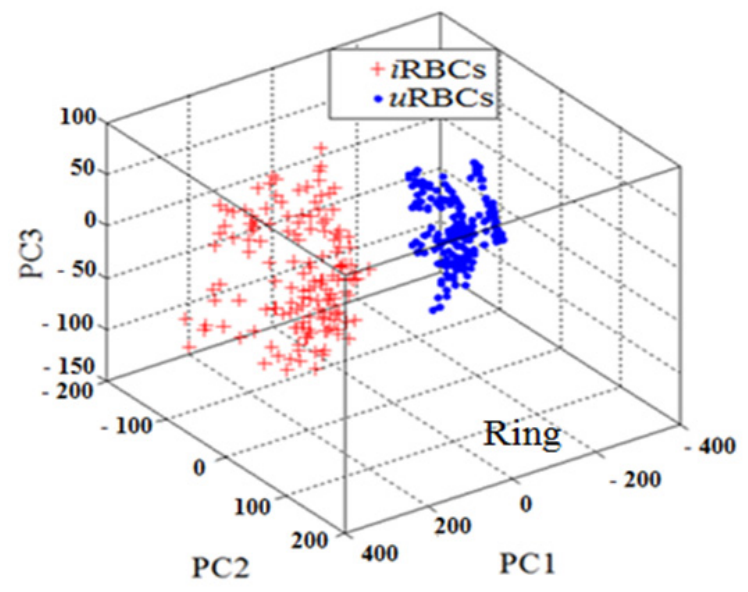

(a)

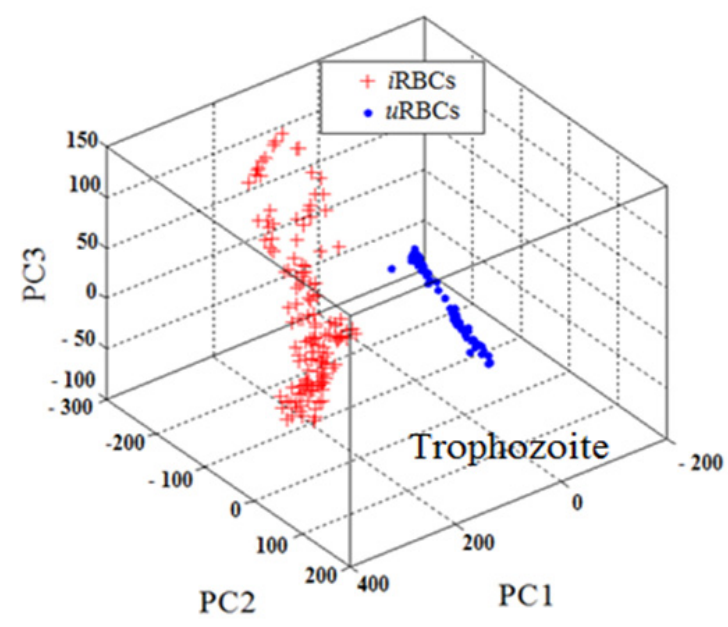

(b)

Figure 5. Scatter plot of the first three principal components of (a) ring stage and (b) trophozoite stage of $P$. falciparum infected RBCs ( $i$ RBCs) and uninfected RBCs ( $u$ RBCs) at $435 \mathrm{~nm}$ spectral band

On the other hand, the trophozoite stage of the parasite has the second and third coefficients of PC1, being positive and fairly significant in magnitude. This indicates that PC1 is proportional to the transmitted light intensities by $i$ RBCs and $u$ RBCs. 


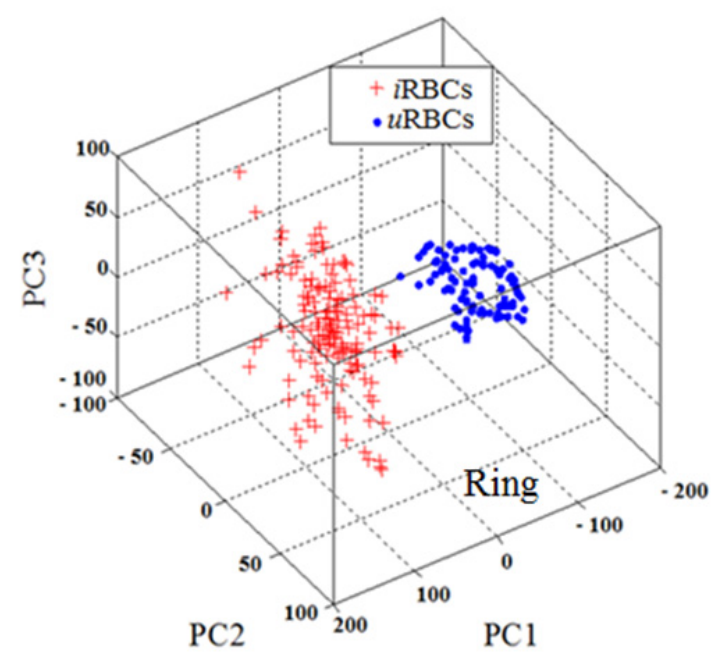

(a)

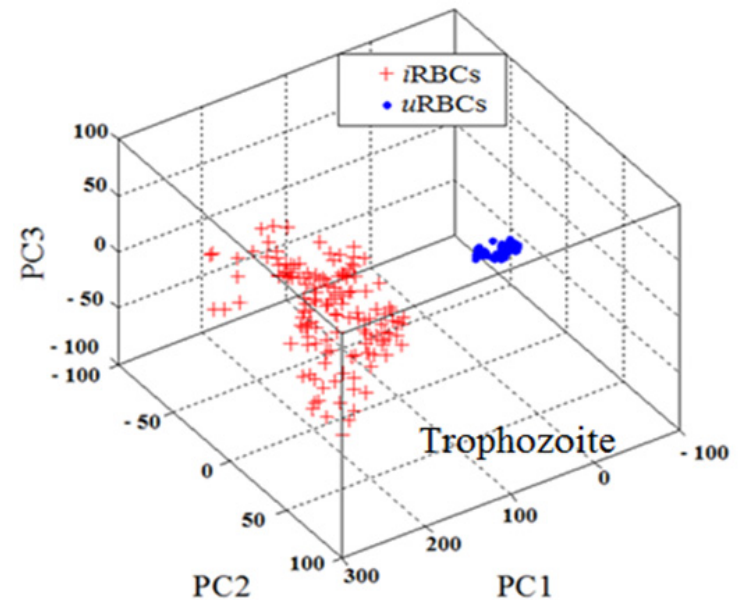

(b)

Figure 6. Scatter plot of the first three principal components of (a) ring stage and (b) trophozoite stage of $P$. falciparum infected RBCs ( $i$ RBCs) and uninfected RBCs $(u$ RBCs $)$ at $660 \mathrm{~nm}$ spectral band

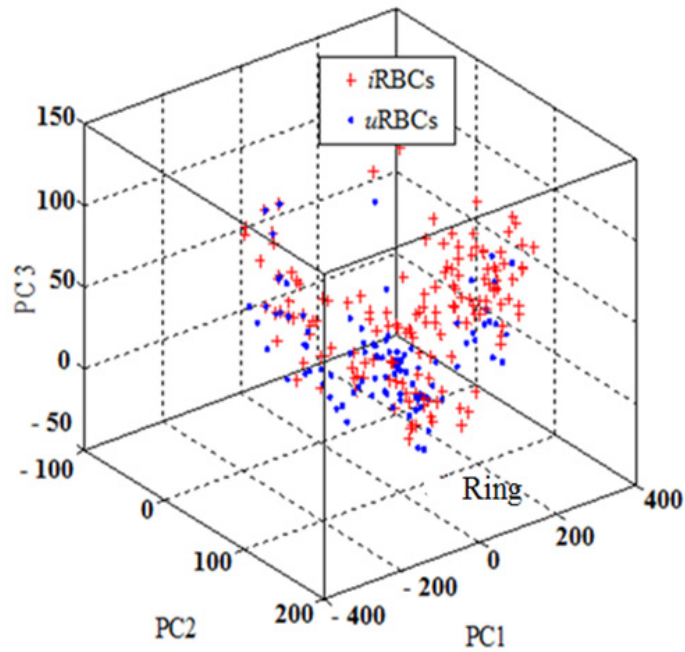

(a)

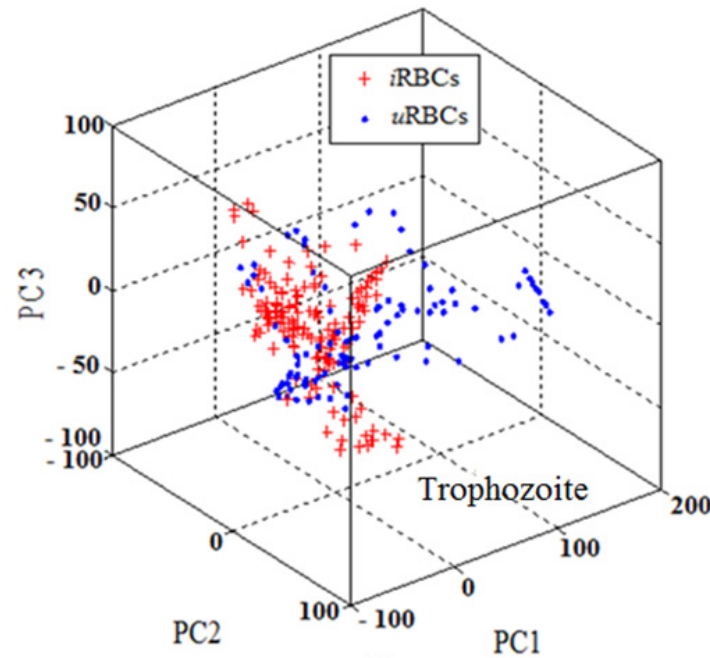

(b)

Figure 7. Scatter plot or une iirst three principal components of (a) ring stage and (b) trophozoite stage of $P$. falciparum infected RBCs ( $i$ RBCs) and uninfected RBCs ( $u$ RBCs) at $470 \mathrm{~nm}$ spectral band

From Figure 7, the $i \mathrm{RBCs}$ at both ring and trophozoite stages cannot be discriminated, that is there is no discrete separation pattern between $i \mathrm{RBCs}$ and $u \mathrm{RBCs}$ at the $470 \mathrm{~nm}$ spectral band. A similar trend is seen in Figure 8 for $700 \mathrm{~nm}$ spectral band, there is no discrete separation pattern between $i \mathrm{RBCs}$ and $u \mathrm{RBCs}$ for both stages. 

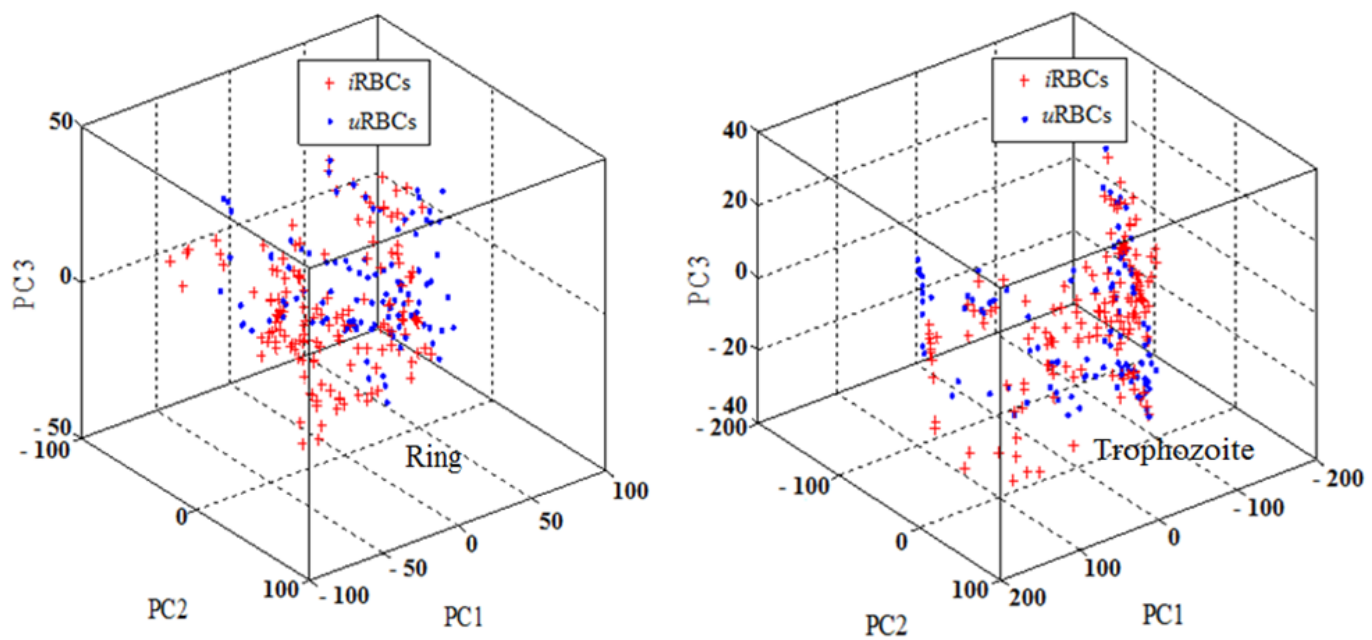

Figure 8. Scatter plot of the first three principal components of (a) ring stage and (b) trophozoite stage of $P$. falciparum infected RBCs ( $i \mathrm{RBCs})$ and uninfected RBCs ( $u$ RBCs) at $700 \mathrm{~nm}$ spectral band

\section{Conclusions}

Using transmitted intensities extracted from multispectral images, four spectral bands: $435 \mathrm{~nm}, 590 \mathrm{~nm}, 625 \mathrm{~nm}$ and $660 \mathrm{~nm}$ have been identified to be markers for distinguishing infected red blood cells $(i \mathrm{RBCs})$ and uninfected red blood cells ( $u$ RBCs) in ring and trophozoite stages of P. falciparum parasite. The $435 \mathrm{~nm}$ and 660 $\mathrm{nm}$ spectral bands were found to be common markers for the two stages whiles $590 \mathrm{~nm}$ and $625 \mathrm{~nm}$ spectral bands were markers for the ring and trophozoite stages respectively. With principal component analysis (PCA), which accounted for $98.9 \%$ of the total variation of the transmitted light intensities, 3 PCs confirmed these spectral bands as markers in the scatter plots. These markers offer a potential diagnostic tool for discriminating $i$ RBCs and $u$ RBCs, as well distinguishing ring and trophozoite stages. The analysis may be implemented in the field by any trained personnel.

\section{Acknowledgments}

The authors wish to express their appreciation to the Office of External Activities (OEA) and Associate scheme of Abdus Salam ICTP, Trieste, Italy for funding. We wish to express our appreciation to International Programme for Physical Sciences (IPPS), International Sciences Programme (ISP), Uppsala University, Sweden and Japan International Cooperation Agency (JICA) for funding and donation of microscopes. Our gratitude goes to Sune Svanberg, Mikkel Brydegaard and Aboma Merdasa, all of Division of Atomic Physics, Lund University, Sweden. Also, to Hiran Jayaweera, Department of Physics, University of Colombo, Sri Lanka for the support. The efforts of all members of the African Spectral Imaging Network (AFSIN) are appreciated.

\section{References}

Amexo, M., Tolhurst, R., Barnish, G., \& Bates, I. (2004). Malaria misdiagnosis: effects on the poor and vulnerable. Lancet, 364, 1896-1898. http://dx.doi.org/10.1016/S0140-6736(04)17446-1

Arora, S., Park, S. H., Mauser, J., Chakrabarti, D., \& Schulte, A. (2011). Micro-Spectroscopy of Single Erythrocytes. Infected with the Malaria Parasite. International Conference on Nanotechnologies and Biomedical. Engineering, Chişinău, Republic of Moldova. Retrieved from http://www.1cellonelight.com/pdf/mic_rbc3\%5B1\%5D2012Schulte.pdf

Brydegaard, M., Merdasa, A., Jayaweera, H., Ålebring, J., \& Svanberg, S. (2011). Versatile multispectral microscope based on light emitting diodes. Rev. of Sci. Instr., 82, 1231061-12310613. http://dx.doi.org/10.1063/1.3660810

Coffey, V. C. (2012). Multispectral imaging moves into the mainstream. Opt. and Photo News, 23, 18-24. http://dx.doi.org/10.1364/OPN.23.4.000018

Goldberg, D. E., Slater, A. F. G., Cerami, A., \& Henderson, G. B. (1990). Hemoglobin degradation in the malaria parasite Plasmodium falciparum: An ordered process in a unique organelle. Biochem., 87, 2931-2935. http://dx.doi.org/10.1073/pnas.87.8.2931 
Graves, E. E., Ripoll, J., Weissleder R., \& Ntziachristos, V. (2003). A submillimeter resolution fluorescence molecular imaging system for small animal imaging. Med. Phys., 30, 901-911. http://dx.doi.org/10.1118/1.1568977

Hay, S. I., Guerra, C. A., Tatem, A., Noor, A. M., \& Snow, R. W. (2004). The global distribution and population at risk of malaria: past, present and future. Lancet Infect. Dis., 4, 327-336. http://dx.doi.org/10.1016/S1473-3099(04)01043-6

Hiraoka, Y., Shimi, T., \& Haraguchi, T. (2002). Multispectral imaging fluorescence microscopy for living cells. Cell. Struct. Funct., 27, 367-374. http://dx.doi.org/10.1387/ijdb.072351jr

Hu, Y., Wu, Q., Liu, S., Wei, L., Chen, X., Yan, Z., ... Ding, Y. (2005). Study of Rice Pollen Grains by Multispectral Imaging Microscopy. Micro. Res. and Tech., 68, 335-346. http://dx.doi.org/10.1002/jemt.20256

Levenson, R. M., \& Mansfield, J. R. (2006). Multispectral imaging in biology and medicine: Slices of life. Cytometry A, 69, 748-758. http://dx.doi.org/10.1002/cyto.a.20319

Levenson, R. M., Lynch, D. T., Kobayashi, H., Backer, J. M., \& Backer, M. V. (2008). Multiplexing with Multispectral Imaging: From Mice to Microscopy. ILAR J., 49, 78-88. Retrieved from http://www.microscopyu.com/references/pdfs/Levenson_etal_ILAR_J_49-78-2008.pdf

Makler, M. T., Palmer, C. J., \& Ager, A. L. (1998). A review of practical techniques for the diagnosis of malaria. Ann. of Trop. Med., \& Parasitol., 92(4), 419-433. Retrieved from http://www.researchgate.net

Mansfield, J. R., Gossage, K. W., Hoyt, C. C., \& Levenson, R. M. (2005). Autofluorescence removal, multiplexing, and automated analysis methods for in-vivo fluorescence imaging. J. Biomed. Opt., 10(4), 041207. http://dx.doi.org/10.1117/1.2032458

Moore, L. R., Fujioka, H., Williams, P. S., Chalmers, J. J., Grimberg, B., Zimmerman, P. A., \& Zborowski, M. (2006). Hemoglobin degredation in malaria-infected erythrocytes determined from live cell magnetophoresis. The FASEB J., 20, 747-749. http://dx.doi.org/10.1096/fj.05-5122fje

Omucheni, D. L. (2012). Multispectral Imaging of Human Blood Media Applied to Malaria Diagnostics. Master of Science (M.Sc) Thesis in Physics, University of Nairobi. Retrieved from http://erepository.uonbi.ac.ke:8080/xmlui/handle/123456789/6889

Paton, D., Faragher, B., Mustaffa, K. M. F., Szestak, T., Barrett, S. D., \& Craig, A. G. (2011). Automated counting for Plasmodium falciparum cytoadherence experiments. Malar. J., 25, 1-6. Retrieved from http://www.malariajournal.com/content/10/1/91

Rice, B. W., Cable M. D., \& Nelson, M. B. (2001). In vivo imaging of light-emitting probes. J. Biomed. Opt., 6, 432-440. http://dx.doi.org/10.1117/1.1413210

Ross, N. E., Pritchard, C. J., Rubin, D. M., \& Duse, A. G. (2006). Automated image processing method for the diagnosis and classification of malaria on thin blood smears. Med. and Biol. Eng. and Comp., 44, 427-436. http://dx.doi.org/10.1007/s11517-006-0044-2

Sachs, J., \& Melaney, P. (2002). The economic and social burden of malaria. Malar. J., 415, 680-685. http://dx.doi.org/10.1038/415680a

Savkare, S. S., \& Narote, S. P. (2011). Automatic Detection of Malaria Parasites for Estimating Parasitemia. Inter. J. of Comp. Sci.and Sec. (IJCSS), 5, 310-315. Retrieved from http://cscjournals.org/csc/manuscript/Journals/IJCSS/volume5/Issue3/IJCSS-480.pdf

Serebrennikova, Y. M., Patel, J., \& Garcia-Rubio, L. H. (2010). Interpretation of the ultraviolet-visible spectra of malaria parasite Plasmodium falciparum. Appl. Opt., 49, 180-188. http://dx.doi.org/10.1364/AO.49.000180

Teikari, P. (2008). Multispectral imaging. Course project for AS-75.2128 imaging and display technology, Helsinki University of Technology. Retrieved from http://www.petteri-teikari.com/pdf/Teikari_Multispectral_Imaging.pdf

Tek, F., Dempster, A., \& Kale, I. (2009). Computer vision for microscopy diagnosis of Malaria. Malar. J., 8, 1-14. http://dx.doi.org/10.1186/1475-2875-8-153

Weatherall, J. D., Miller, H. L., Baruch, D. I., Marsh, K., Doumbo, K. O., Casals-Pascual, C., \& Roberts, D. J. (2002). Malaria and the Red Cell. Hematology, Am. Soc. of Hem., 35-57. Retrieved from http://asheducationbook.hematologylibrary.org/content/2002/1/35.full.pdf 
Zhang, H. F., Maslov, K., Stoica, G., \& Wang, L. V. (2006). Functional photoacoustic microscopy for high-resolution and noninvasive in vivo imaging. Nature Biotechnol., $24,848-851$. http://dx.doi.org/10.1038/nbt1220

Zhang, H. F., Maslov, K., \& Wang, L. V. (2007). In vivo imaging of subcutaneous structures using functional Zhang, photoacoustic microscopy. Nat. Protoc., 2, 797-804. http://dx.doi.org/10.1038/nprot.2007.108

Zhang, Y., Hong, H., \& Cai, W. (2011). Photoacoustic Imaging. Col. Spr. Harb. Protoc., 1015-1025. http://dx.doi.org/10.1101/pdb.top065508

Zhou, L., \& El-Deiry, W. S. (2009). Multispectral Fluorescence Imaging. J. of Nucl. Med., 50, $1563-1566$. http://dx.doi.org/10.2967/jnumed.109.063925

\section{Copyrights}

Copyright for this article is retained by the author(s), with first publication rights granted to the journal.

This is an open-access article distributed under the terms and conditions of the Creative Commons Attribution license (http://creativecommons.org/licenses/by/3.0/). 